\title{
Introduction - Setting the Evaluation Use Context
}

\author{
Cheryl Poth \\ University of Alberta, Department of Educational Psychology, \\ Faculty of Education \\ Michelle Searle \\ Independent Consultant
}

This special issue honours Dr. Lyn Shulha's 25 -year contributions to the Canadian field of program evaluation by bringing together the perspectives of authors from across North America to identify Dr. Shulha's influence on their thinking and evaluation practices. Dr. Shulha's scholarship is best described as a nonlinear influence because the effect of her work on evaluators' thinking about collaboration, use, standards, and innovation cannot be directly traced. Rather, her scholarly work and mentoring efforts have enhanced the field in Canada and beyond while also leading to more widespread adoption of high-quality evaluation practices promoting use through collaboration and learning. These ideas related to evaluation use and high-quality learning opportunities have important implications for the future of evaluation practice in Canada (e.g., Buchanan \& Kuji-Shikatani, 2014; Stevahn, King, Ghere, \& Minnema, 2005) and are aligned with calls for enhanced initial and professional learning within the Canadian context (e.g., Consortium of Universities for Evaluation Education, 2011; Kuji-Shikatani, McDavid, Cousins, \& Buchanan, 2013).

Our initial impetus for this special issue germinated from our participation as invited contributors to the Canadian Educational Evaluation Symposium: Exploring Past and Future Directions to Optimize Evaluation Use held on September 18, 2015 in Kingston, Ontario. During this day academic and community-based colleagues as well as past and present graduate students had the opportunity to engage in critical conversations about fundamental and emerging issues in program evaluation. Another feature of the day was to celebrate and highlight Lyn Shulha's contributions and her influence on their evaluation work. What made the outcomes of this day so unique were the diverse perspectives afforded by attendees in terms of geography (i.e., local, national, and international were all represented) and expertise (e.g., health, education, government, etc.). Drs. Rodney Hopson and Liying Cheng are credited with initially suggesting the idea for a special issue, and attendees agreed that an outlet to share the innovative practices discussed was necessary.

As co-editors we write from the perspective of former graduate students who studied and worked with Dr. Shulha throughout our graduate degrees at Queen's 
University. We were privileged to have our development as evaluators shaped by our interactions with Dr. Shulha. As a mentor for many graduate students and colleagues, she facilitated learning experiences essential for pursuing careers in evaluation by developing knowledge and skills, and then creating opportunities for real-world applications. She was as well known for her academic expertise as for her extremely supportive and practical supervisory approach. Dr. Shulha taught us that in evaluation, the saying "it depends" is attributable to the uniqueness of each evaluation context. She also taught us that evaluation is an applied art and that, while elaborate ruminations are possible, serving the clients' needs must remain central to our work. Through her leadership, Dr. Shulha inspired people to find their own unique ways to contribute to the field of evaluation practice. For us, our commitment to enhancing evaluation use and advancing evaluation practices is demonstrated by our work as practitioners in diverse contexts, as instructors in the classroom, and as contributors to the literature.

We agreed to take on the coordination efforts for this special issue, and to our delight (and surprise) we received acceptances from all of the original invited contributors. These initial invitees were chosen from a larger list of participants in the Canadian Educational Evaluation Symposium because they represented diverse roles (e.g., academics, students, community partners), potential topics, and geographical locations. In addition, we invited contributors that would represent the core areas of Dr. Shulha's work and, as such, demonstrate her influence on the areas of use and collaboration in the field of evaluation. To begin, we solicited titles and brief abstracts and submitted the proposal for a special issue. Once the proposal was accepted, we invited the authors to prepare manuscripts that were then subjected to three reviews as part of a double-blind peer review process; it is noteworthy that we sought reviewers who are recognized as experts in the field of evaluation. We are proud to present the seven invited manuscripts embodying the superb efforts of all our authors in attending to the thoughtful feedback from our reviewers in five articles, a practice note, and a closing commentary.

To enhance the range of voices that could be accommodated as manuscripts, we invited additional symposium participants to share their musings related to Dr. Shulha's work and her contributions to the field of evaluation. Selections of these stories have been interwoven into this editorial to resonate two core themes presented in this issue: collaboration and learning. Bringing together the voices and perspectives of varied people from diverse disciplines engaged in thoughtful reflection embodies the manner in which Dr. Shulha, in our perspective, constructs her evaluation scholarship and practice. In creating this editorial and this special issue, we honour Dr. Shulha's commitment to evaluation as a form of scholarship that nudges at the boundaries of research conventions and extends understanding about evaluation use by encouraging collaborative processes and learning from ongoing reflection. In the conversations we hope this special issue will provoke, we envision a continued broadening of the field of evaluation where possibilities for collaborating in the generation, and use, of evaluation knowledge leads to continual influence and improvement of the world we live in. 


\section{INTERWEAVING SCHOLARSHIP AND STORIES}

As the manuscripts in this special issue attest, Dr. Shulha has contributed significantly to our understandings in the areas of evaluation use (Cousins \& Shulha, 2006), collaborative practice (e.g., Shulha, Whitmore, Cousins, Gilbert, \& al Hudib, 2016; Shulha \& Wilson, 2003), and evaluation standards (e.g., Yarbrough, Shulha, \& Caruthers, 2004; Yarbrough, Shulha, Hopson, \& Caruthers, 2010). Working on this special issue has reminded us of the power of persistence and the cumulative effect that can be produced over a productive career.

The opening article- "Developing the Program Evaluation Utility Standards: Scholarly Foundations and Collaborative Processes"-provides a unique perspective from which to launch this special issue about Dr. Shulha's collaborative contribution to the third edition of The Program Evaluation Standards (Yarbrough et al., 2010) and specifically her work on the Utility standards, by her co-author Dr. Don Yarbrough. This work has played an influential role in guiding evaluator practice from all over the world; including in Canada where the third edition of the Standards is embedded within the descriptions of the Competencies for Canadian Evaluation Practice. Another collaborator on the revised standards, Dr. Rodney Hopson, Professor at George Mason University, reflects in the following story on how the values of learning and inclusion have permeated Dr. Shulha's approach:

The work we did on the third edition of the Program Evaluation Standards were like family reunions and I cherish that deliberate and careful attention to scholarship modeled for us in understanding the depth of utility! Lyn is a real ground breaker in her work on focusing on evaluation use beyond a unitary function to a multidimensional function one. One of my favourite quotes, and true to Lyn's form, is the one from an American Evaluation Association paper in 1994 when she wrote that "Wishing an evaluation to be participatory, does not make it so!” That quote epitomizes Lyn and her hope for the field. We evaluators can do more to ensure that our work is useful, quality, contextual, complex, meaningful, credible, relevant, and timely. And we have Lyn to thank for reminding us as we build the discipline and field for years to come.

Relationships are central to the work Dr. Shulha has undertaken, and the importance of context and connections is also important to many of the articles featured in this issue. Both relationships and the concept of brokering are essential to Donnelly and Searle in the second article, "Optimizing Use in the Field of Program Evaluation by Integrating Learning from the Knowledge Field," where they imagine the future contexts of interwoven fields of knowledge and program evaluation. From their perspectives as former students, the authors point to Dr. Shulha's championing of accessible evaluation scholarship to a range of stakeholders as influential to their own work. They trace the key developments in their understandings of the role of evaluators in creating bridges between individual and organizational learning to promote knowledge mobilization. They make a case for evaluation as knowledge work because of the unique positioning of evaluation in the pursuit of systematic forms of inquiry and decision making that provides a disciplinary bridge. A Queen's University colleague, Dr. Chris 
DeLuca, encapsulates the reach of Dr. Shulha's evaluation scholarship in the following summary:

The worlds of educational assessment and evaluation are unquestionably complex. However, Lyn is able to see through the complexity and keep focused on the enduring goal embedded in all evaluation and assessment activities: the goal of learning. By prioritizing client, student, and educator learning through all of her work, Lyn is able to make program evaluation a valued and appreciated process within educational contexts.

The next two empirical articles highlight novel understandings gleaned from using collaborative approaches to evaluation. In their article, "Reflections on the Meanings of Success in Collaborative Approaches to Evaluation: Results of an Empirical Study," authors Whitmore, Al Hudib, Cousins, Shulha, and Gilbert provide further analysis of data from previous work that developed a set of evidencebased principles. Asking the question "How do evaluators using collaborative approaches to evaluation (CAE) define success?" they explore determinants of and criteria for "success" from the perspective of evaluators' responses $(N=320)$ to their survey about practical experience with CAE, taking into account the context of the respondents' case examples. Whitmore and her colleagues provide a conceptual framework combining the processes and outcomes related to criteria for success which provides a useful framing for reading the next article. Searle and her colleagues use the principles from CAE within a developmental evaluation in an article titled "A Case Study of the Guiding Principles for Collaborative Approaches to Evaluation in a Developmental Evaluation Context." Data from an 18-month period involving collaboration between a university-based evaluation team and the program team from a national organization are used to explore how the principles strengthen collaboration and facilitate evaluative thinking in this developmental evaluation. The authors recognize Dr. Shulha's influence as their key mentor responsible for instilling the value of enhancing scholarship through application of evaluation theories and ongoing development of the evaluation standards and competencies of the field.

Collaboration is a central feature of this issue because it has played a significant role in shaping Dr. Shulha's evaluation experiences and is deeply entrenched in the way she views evaluation practice and theorizing. Dr. Shulha's commitment to the people, the projects, and the broader field of evaluation are apparent when she is working with diverse stakeholders. Collaborative networks promote evaluation use and influence by drawing on the expertise and experiences of relevant stakeholders while channelling their work toward a shared vision about the value of systematic processes and data-informed decision-making. We foresee that the value of learning grounded in networks of people within academic and practitioner settings as well as those established across disciplines will be critical to promoting the connectedness required for continued development of evaluation use and influence. As a former Queen's University colleague, Dr. Bob Wilson reflects on an influential lesson related to collaboration in the following description: 
When Lyn was enrolled in a doctoral programme, she was progressing well through the work, and nearing completion of the data-gathering, in a school where the principal had invited her in to work with teachers, I was stunned to receive an emotional call from her: the principal, perhaps fearing what would happen to his own control if his teachers continued to grow in confidence, kicked Lyn out and told her not to return. Fearing the worst-no thesis, no degree-we met to discuss the situation, collaboratively of course. Together, we coined a mantra that served her well in all her future work: "It's all data!" Why did he feel he had to dismiss her? What could she have done better in keeping him involved? How could she use the experience in future work? In fact, that event turned out to be seminal to her thesis and practice.

The role of mentorship is emphasized in the final empirical article, "Influential Mentoring Practices for Navigating Challenges and Optimizing Learning During an Evaluation Internship Experience." Poth, Anderson-Draper, and El Hassar explore quality indicators of an internship experience through the analysis of interviews with an intern, mentor, and coordinator, supplemented by field notes. Three key features are discussed related to influential mentoring practices: orientation to workplace context, autonomy of supervisory approach, and planning for evaluation agility. Much discussion has focused on Dr. Shulha's mentoring between teacher-students, yet a Queen's University colleague, Dr. Liying Cheng, shares the impact of scholar-scholar mentoring in the following account:

When I think about Lyn, I think about legacy, impact, balance, and sense of humour. Lyn represents program evaluation. Indeed, for many of us, Lyn's legacy is based on her program evaluation work. Not many academics can claim to have made such defining contributions to our field. Impact is now a buzzword in Education. I am, however, not talking about causal relationships or impact factors in terms of publications and grants. I am talking about the tremendous positive influence Lyn has had on teachers, academics, and the next generation of program evaluators. Lyn has showed me how to work positively and professionally with staff, faculty members, and graduate students. From time to time, Lyn also shared some of her stories with me. Her narratives always reminded me of the tremendous importance of balancing life and work, joy and frustration, encouragement and disappointment. Lyn has taught me how to work well in teams, how to follow, and how to lead. I could not have asked for-nor could I imagine-a better mentor and colleague for me than Lyn.

In the sole practice note, "The Oral History of Evaluation: An Interview with Lyn Shulha," Lam was inspired by the Oral History in Evaluation Project as way to reflect learning opportunities over a professional career. He offers a rich historical perspective to the development of the field, especially as recounted in the context of Canadian evaluation, the events and experiences that have shaped Dr. Shulha's career. It offers instructive lessons for evaluators, both novice and experienced, on launching and sustaining a career as an evaluation practitioner and researcher.

Many of these ideas about the value of blending theory and practice, listening and sharing, as well as acting and reflecting are echoed in the words of Dr. Shulha's colleague Dr. Don Klinger at Queen's University. Dr. Klinger shared the following story to extend understanding about blending evaluation and research to impact scholarship. 
Lyn's questions and comments create thoughtful dialogues and reflections; so much so, it is rumored that she has run out of gas on the 401 freeway in Toronto while deep in discussion. My own discussions with Lyn Shulha have impacted both my evaluation work and my work with classroom and large-scale assessment and testing. The lexicon and foundations of developmental and formative evaluation models continually shape my own thinking about assessment practices and, perhaps more importantly, assessment use. The two of us have worked together as instructors and research colleagues, and in every context, the end result has been a shift in my own thinking. I have witnessed these same shifts in others that Lyn has worked with. And these shifts are not just in people but also in organizations. As one critical example, the Ontario Ministry of Education now requires evaluation projects they fund to specifically highlight how the evaluation will serve a developmental purpose. This was not at all the case when we first began completing evaluation work with the Ontario Ministry of Education. These shifts highlight the influence of Lyn and her colleagues and alter the way that program evaluation is used in educational contexts; we are all richer for it.

Dr. Shulha's contribution as a founder of the Assessment and Evaluation Group at Queen's University typifies her commitment to learning. As a scholarly family, the group offers an inclusive space for kinship where professors, students, and others who are interested in assessment and evaluation find connection as well as unity in their diverse ideas, approaches, and methods. In a closing commentary, Greene reflects on Dr. Shulha's influence on the field and on her personally over the past quarter of a century. She highlights Dr. Shulha's work in three areas: evaluation as collaborative practice, evaluation usefulness and use, and contributions of evaluation standards to evaluation as a profession and a practice. She also provides a perspective about her as a friend and colleague and the warmth that exudes across both these roles. Rich relationships that enhance evaluation use and influence are also evident in the experience shared by Dr. Keiko KujiShikatani from the Ministry of Education:

Last year during the Evaluation Use Thematic Interest Group meeting at the American Evaluation Association, we honoured Lyn's contributions. During a discussion about the future of the group we had great fun hearing from Don Yarbrough, Valerie Caracelli, Michael Quinn Patton, Jean King, Rodney Hopson, Karen Kirkhart, Susan Tucker, Erin Burr, and Brad Cousins, who sent a written response because he could not be there. We concluded that a name change was necessary and Michael Patton pulled together the rationale, "Arguably the most important conceptual development in the study and theory of evaluation utilization over the last 15 years has been the expansion, both empirically and conceptually, to include influence as a core dimension of utilization. The TIG name should reflect that important development."

The new name adopted for the Thematic Interest Group was "Use and Influence of Evaluation," and from this story we can infer the scope of Dr. Shulha's reach and the impact of her efforts on a global scale.

We are pleased to introduce Dr. Shulha's work and her impact on others and to share these articles because of the usefulness for advancing evaluation use and 
our understandings of Dr. Lyn Shulha's contribution to the current generation of Canadian program evaluators and researchers. Evident from the articles in this issue is that understanding and promoting evaluation use requires attention to the approaches and methods of evaluation applied in a range of contexts for a spectrum of purposes in ways that we are only beginning to understand. In collaborating with others, whether they are practitioners in the field, students, or colleagues from the field of evaluation, education, or health, Dr. Shulha focuses on building relationships, so that those working with her can act systematically in the ways they collect and use data for decision-making about programming. Her efforts in the field of evaluation reflect the relational, dynamic, and interconnected ways in which she views the world. She is guided by a commitment to questioning, listening, and reflecting as ways of understanding. By holding these commitments in her scholarship and her professional practice, she enhances the possibility of evaluation use by encouraging and modelling decisions informed by data or taking informed actions with a view to intended consequences.

Let us come together and imagine a future of evaluation use and influence where evaluators are skilled at flexibly positioning their evaluation work within applied contexts and yet guided by standards, competencies, and principles established by the field of evaluation. An evaluator focused on use and influence is one who is ethical, rigorous, and yet flexible; a professional who possesses both the capacity of skilled evaluation practice and the imagination for innovative scholarship. This special issue highlights Dr. Shulha's influence and further establishes a network of evaluation scholars by providing a shared goal for sustained interactions around evaluation ideas. The power of collaborations will need to be harnessed for the future growth of the field of evaluation. Collaborating presents both opportunities and challenges (e.g., Bowen \& Martens, 2006; Cousins \& Whitmore, 1998; O'Sullivan, 2004; Shulha \& Cousins, 1997). Keeping pace with the fluidity of collaborative styles now possible, and even necessary, requires ongoing learning and reflection (Canadian Evaluation Society, 2010; Shulha et al., 2016; Shulha \& Wilson, 2003). In today's increasingly complex and interdependent work, collaboration leverages the expertise and experiences of many for the purposes of ongoing learning (Preskill, Zuckerman, \& Matthews, 2003; Torres \& Preskill, 2001). Moving forward, successful collaborations will continue to promote learning by increasing transparency for funders while using multiple modalities in evaluation processes and products to engage stakeholders, participants, and/or public audiences.

As guest co-editors, we are indebted to the authors and peer reviewers of manuscripts for their willingness to participate in this important endeavour and, of course, to the Canadian Journal of Program Evaluation and specifically editorin-chief, Robert Schwartz, for supporting our efforts. We are grateful that this process has included many others who have acted as sounding boards for ideas and reviewers for pieces, responded to technical questions, or contributed pieces for inclusion in this editorial. There are considerable differences that characterize the pieces in this issue and the construct of evaluation use more broadly. These 
differences, rather than dividing our ideas, make clear the value of having a broad perspective, a strong group of colleagues, the ability to collaborate, standards to guide our practice, and the willingness to reflect-these are the lasting influences of Dr. Shulha's work in evaluation use. We now invite you to enhance your engagement with the ideas presented in this issue by following Dr. Shulha's leadership; embracing a learning stance, reflecting frequently, and collaboratively discussing ideas with evaluation colleagues who are both inside and outside the academic environment.

\section{ACKNOWLEDGEMENTS}

In recognition of the great deal of work completed behind the scenes for any special issue, we wish to extend our heartfelt thanks to the Canadian Journal of Program Evaluation editor-in-chief, Robert Schwartz, Editorial Assistant Emily Taylor, the Associate Editors and Editorial Board Members (see CJPE website). We truly appreciate the support for bringing our idea to fruition in honouring Dr. Lyn Shulha's contribution to the field of evaluation. In closing, we hope that the articles in this issue help readers to think differently about evaluation use, its application to their own work, and ultimately encourage innovation in evaluation use research.

\section{REFERENCES}

Bowen, S., \& Martens, P. J. (2006). A model for collaborative evaluation of universitycommunity partnerships. Journal of Epidemiology and Community Health, 60(10), 902-907. http://dx.doi.org/10.1136/jech.2005.040881

Buchanan, H., \& Kuji-Shikatani, K. (2014). Evaluator competencies: The Canadian experience. Canadian Journal of Program Evaluation, 28(3), 29-47.

Canadian Evaluation Society. (2010). Competencies for Canadian evaluation practice. Retrieved from http://www.evaluationcanada.ca/txt/2_competencies_cdn_evaluation_ practice.pdf

Consortium of Universities for Evaluation Education. (2011). Framework for collaboration on shared inter-university graduate evaluation education courses. Retrieved from http://www.evaluationeducation.ca/documents/CUEE_Annual_Report_2014-2015. pdf

Cousins, J. B., \& Shulha, L. M. (2006). A comparative analysis of evaluation utilization and its cognate fields of inquiry: Current issues and trends. In I. Shaw, M. M. Mark, \& J. Greene (Eds.), Handbook of evaluation: Program, policy and practices (pp. 266-291). London, UK: Sage. http://dx.doi.org/10.4135/9781848608078.n12

Cousins, J. B., \& Whitmore, E. (1998). Framing participatory evaluation. New Directions for Evaluation, 1998(80), 5-23. http://dx.doi.org/10.1002/ev.1114

Kuji-Shikatani, K., McDavid, J., Cousins, J. B., \& Buchanan, H. (2013). Consortium of Universities for Evaluation Education and its impacts on professionalizing evaluation in Canada. Nihon Hyouka Kenkyuu, 12(2), 11-22. 
O'Sullivan, R. G. (2004). Practicing evaluation: A collaborative approach. Thousand Oaks, CA: Sage. http://dx.doi.org/10.4135/9781412985468

Preskill, H., Zuckerman, B., \& Matthews, B. (2003). An exploratory study of process use: Findings and implications for future research. American Journal of Evaluation, 24(4), 423-442. http://dx.doi.org/10.1177/109821400302400402

Shulha, L., \& Cousins, J. B. (1997). Evaluation use: Theory, research, and practice since 1986. American Journal of Evaluation, 18(1), 195-208. http://dx.doi.org/10.1177/109821409701800121

Shulha, L. M., Whitmore, E., Cousins, J. B., Gilbert, N., \& al Hudib, H. (2016). Introducing evidence-based principles to guide collaborative approaches to evaluation: Results of an empirical process. American Journal of Evaluation, 37(2), 193-215. http://dx.doi. org/10.1177/1098214015615230

Shulha, L. M., \& Wilson, R. J. (2003). Collaborative mixed methods research. In A. Tashakkori \& C. Teddlie (Eds.), Handbook of mixed methods in social \& behavioral research (pp. 639-670). Thousand Oaks, CA: Sage.

Stevahn, L., King, J. A., Ghere, G., \& Minnema, J. (2005). Establishing essential competencies for program evaluators. American Journal of Evaluation, 26(1), 43-59. http:// dx.doi.org/10.1177/1098214004273180

Torres, R. T., \& Preskill, H. (2001). Evaluation and organizational learning: Past, present, and future. American Journal of Evaluation, 22(3), 387-395. http://dx.doi. org/10.1177/109821400102200316

Yarbrough, D. B., Shulha, L. M., \& Caruthers, F. (2004). Background and history of the joint committee's program evaluation standards. New Directions for Evaluation, 104(104), 15-30. http://dx.doi.org/10.1002/ev.133

Yarbrough, D. B., Shulha, L. M., Hopson, R. K., \& Caruthers, F. A. (2010). The program evaluation standards: A guide for evaluators and evaluation users (Vol. 3). Thousand Oaks, CA: Sage. 